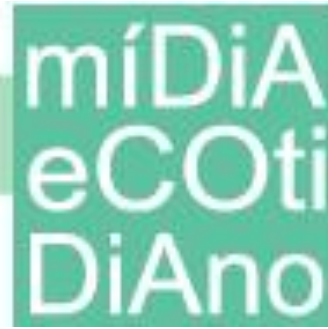

Revista Eletrônica do Programa de Pós-Graduação em Mídia e Cotidiano Artigos Seção Livre

Número 2. 163-181 Junho 2013

(C) 2013 by UFF

\title{
APRENDIZAGEM, MOBILIDADE E CONVERGÊNCIA: Mobile Learning com Celulares e Smartphones
}

\section{LEARNING, MOBILITY AND CONVERGENCE: Learning with Mobile Phones and Smartphones}

\author{
ANA GRACIELA M. F. DA FONSECA ${ }^{1}$
}

\begin{abstract}
Resumo: O uso de aparatos de comunicação para o ensino-aprendizagem não se trata de uma novidade, bem como o fascínio que exercem e o status de "solução" comumente atribuído a eles no contexto educacional. Com a diversificação e evolução tecnológica desses aparatos, reunidos na denominação Tecnologias de Informação e Comunicação (TIC`s), expectativas e argumentos vêm sendo gerados em relação à apropriação das TIC`s para fins de ensino-aprendizagem. Este artigo aborda o Mobile Learning, aprendizagem através de dispositivos móveis, como celulares e smartphones. Para isso, apresenta exemplos que permitem avaliar perspectivas e tensões que cercam o uso desses aparelhos como objeto de aprendizagem.
\end{abstract}

Palavras-chave: tecnologia; mobile learning; telefone celular; ensino-aprendizagem.

\begin{abstract}
The use of communication devices for teaching and learning is not a novelty, neither the fascination they cause and the status of "solution" that is commonly attributed to them in the educational field. With the diversification and technological growth (development) of these devices, grouped in the name of Technologies of Information and Communication (TIC`s), expectations and arguments have been raised regarding the appropriation of TIC's for teaching and learning. This article discusses the Mobile Learning, learning through of mobile devices, such as cell phones and smartphones. For this, presents examples for assessing prospects and tensions surrounding the use of these devices as object of learning.
\end{abstract}

Keywords: technology, mobile learning, mobile phone; teaching and learning.

\section{Introdução}

\footnotetext{
${ }^{1}$ Doutoranda em Comunicação Social pela Universidade Metodista de São Paulo, na linha de pesquisa Inovações Tecnológicas na Comunicação Contemporânea, bolsista CAPES, membro do Grupo de Pesquisa TECCCOG - Tecnologia, Comunicação e Ciência Cognitiva. E-mail: ana_gcos@ @otmail.com.
} 


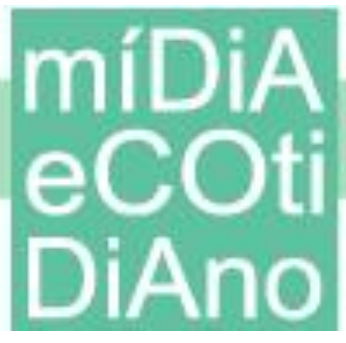

Atualmente é difícil dissociar o cotidiano das novas tecnologias de informação e comunicação, e não tem sido diferente no campo da Educação, embora a presença de aparatos de informação e comunicação no ensino não seja novidade (SENA; BURGOS, 2010), (FREIRE; GUIMARÃES, 2011). Para Lima Junior (2012), nas últimas décadas a sociedade contemporânea absorveu as Tecnologias de Informação e Comunicação (TIC's) em todos os seus segmentos. O motivo para essa disposição está na percepção de que as tecnologias digitais trazem conforto, vantagens competitivas e podem ser obtidas mais facilmente devido à redução dos custos. De acordo com Paulo Freire e Sérgio Guimarães (2011) o uso e a interferência dos meios de comunicação no dia-a-dia de alunos e professores não é uma questão nova. Contudo, é evidente a existência de uma nova dinâmica nessa relação no universo das tecnologias digitais.

Segundo Straubhaar e LaRose (2004) em poucos anos a tecnologia da informação tornou-se parte de nossa vida diária - e promete moldar profundamente o nosso futuro. Nesse sentido, tornam-se comuns estudos voltados para a compreensão sobre os usos das TIC’s em diversas áreas, como na Educação. Podemos destacar nesse contexto, a ascensão dos dispositivos comunicacionais móveis. Convergentes, portáteis e multimídias, esses aparelhos representam um conjunto de alternativas que podem ser exploradas também para a aprendizagem, denominadas de Mobile Learning Aprendizagem Móvel.

Dessa maneira, iniciativas vêm se apropriando, por exemplo, de telefones celulares e smartphones (telefones inteligentes) para o ensino-aprendizagem. Dentre os dispositivos que podem entregar/suportar o Mobile Learning, o telefone celular é sem dúvida o mais popular e acessível. As justificativas para a apropriação do celular para o ensino-aprendizagem seriam: a familiaridade, por ser considerada uma tecnologia amigável e comum no cotidiano, a mobilidade e portabilidade, que permite levá-lo para qualquer parte, os aspectos cognitivos, por meio do contato com uma gama de recursos em vários formatos (texto, som, imagem, vídeo) e a conectividade, através da internet no celular, que amplia as formas de comunicação e o acesso à informação, atributos apontados como potencializadores dessa atividade. 


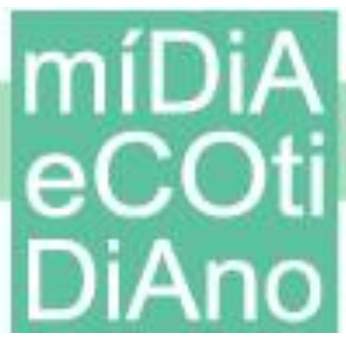

Através da convergência tecnológica, que permitiu agregar sistemas de informática, comunicação e computação, o telefone celular se transformou em um uma central multimídia computadorizada (ANTONIO, 2010). Assim, o aparelho vem sendo reconhecido também como objeto de aprendizagem (TAROUCO et al., 2004) devido a vários recursos disponíveis a partir de uma única tecnologia.

É fato a capacidade de uma tecnologia multifuncional como o telefone celular. Apesar disso, apenas a inserção desta tecnologia em processos de ensino-aprendizagem não garante eficiência e atualização. Em se tratando de tecnologia, o potencial não reside nela própria, e sim na interação com o homem. Desse modo, é preciso que os envolvidos, neste caso, alunos e professores, estejam preparados e dispostos, para que essa apropriação possa de fato representar transformação e gerar ganhos para a Educação. É preciso lembrar que mesmo as tecnologias possuem limitações e não devem ser vistas como solução, um fim. No caso do Mobile Learning, a falta de bateria e banda larga suficiente pode comprometer o trabalho, fundamentais para a mobilidade, acesso e compartilhamento. Principalmente, em relação ao segundo quesito, já que o país ainda padece de um sistema de telefonia móvel satisfatório e com total cobertura do território brasileiro.

Dessa maneira, este artigo buscou mostrar por meio de alguns exemplos, quais as potencialidades e em que contextos o uso de celulares e smartphones podem representar uma alternativa para o ensino-aprendizado, como também tensões e equívocos que cercam o tema.

\section{A evolução do telefone celular}

Para Straubhaar e LaRose (2004) a indústria de telefonia tem grande impacto na trajetória dos meios de comunicação e da sociedade em geral. A infra-estrutura de telecomunicação combinada com tecnologias de computação pode ser considerada o sistema nervoso central da comunicação contemporânea:

A razão é que acreditamos que o telefone é o ponto central no entendimento da mídia de hoje e de amanhã. O telefone antecedeu o 
rádio e a televisão; de fato, o rádio e a televisão foram em grande parte inventados pelos pesquisadores da companhia de telefone. A infra-estrutura através da qual a maioria das novas tecnologias de comunicação faz suas conexões é o telefone. Os aparelhos de fax enviam documentos através de linhas telefônicas. Mensagens via Internet são enviadas por linhas de telefone (2004, p. XVI).

Ainda, de acordo com os autores, o telefone é, ao mesmo tempo, um dos mais antigos e atualizados meios de comunicação. A convergência de sistemas de comunicação, computação e informática transformou o telefone celular em um aparato multifuncional, possibilitando o surgimento de aparelhos smartphone "telefone inteligente".

Para Costella (2002) a distância sempre representou um desafio para as comunicações humanas. Desde os tempos mais remotos, o homem vem idealizando soluções para comunicar-se a distância. Para o autor, o fenômeno da Globalização estreitamento das relações entre países - levou a expansão de formas de comunicação à distância. Dessa maneira, a difusão de tecnologias como o telefone, redes telemáticas ${ }^{2}$ e o celular foram fundamentais e fomentadas para atender essa demanda.

Segundo Straubhaar e LaRose (2004) a tecnologia é um agente de transformação e gera implicações na sociedade. Buscando entender esse fenômeno pelo viés da Filosofia da Tecnologia, uma corrente teórica que visa compreender a tecnologia para além da utilidade no sentido estrito, como o tipo de mundo e o modo de vida que emerge com sua utilização, é possível relacionar a indústria de telefonia, com a visão Aristotélica de tecnologia, como instrumento para que o homem realize plenamente seu ser (LIMA, 2007). Segundo Feenberg (2003) a humanidade é um tipo de animal que trabalha constantemente para transformar a natureza. Outra definição de tecnologia que nos permite analisar o uso da telefonia descrito por Costella (2002) é a de Milton Vargas. Para Vargas "a tecnologia é hoje a atividade de transformação do mundo, resolução de problemas práticos, construção de obras e fabricação de instrumentos, baseada em conhecimentos científicos e por processos cientificamente controlados" (1994, p.20).

\footnotetext{
${ }^{2}$ Descreve a combinação de telecomunicações e computadores (STRAUBHAAR; LAROSE, 2004).
} 


\section{míDiA

Straubhaar e LaRose (2004) apontaram para a transformação do telefone de um instrumento interpessoal de comunicação de voz para uma rede que integra voz, dados e vídeo. Inicialmente, o telefone celular era apenas um aparelho destinado à comunicação de voz. Posteriormente, suas funções foram sendo ampliadas e hoje corresponde ao que André Lemos (2007a) denominou de Dispositivos Híbridos Móveis de Conexão Multirrede (DHMCM). O autor explica que os DHMCM aliam potência comunicativa (voz, texto, foto, vídeo), conexão em rede e mobilidade por territórios informacionais.

Atualmente, o Brasil tem mais telefones celulares que habitantes. Dados da Anatel indicam que o país terminou o mês de março de 2013 com 264,05 milhões de celulares $^{3}$. De acordo com pesquisa realizada pela empresa de segurança digital $F$ Secure, da Finlândia, o Brasil ocupa a quinta posição no ranking em relação a números de celulares e acessos móveis e está em terceiro lugar no quesito acesso de crianças a dispositivos móveis. A União Internacional de Telecomunicações considera que o celular é a tecnologia mais rapidamente adotada na história da humanidade (CASTELLS, 2008), (MERIJE, 2012).

O design e as funcionalidades dos telefones celulares passaram por algumas evoluções, como por exemplo, a execução de toques que reproduzem sons com vocais e instrumentos musicais ao mesmo tempo, a qualidade (resolução) e tamanho dos displays (visor), tornando-os também coloridos e touchscreen (tela sensível ao toque). Além disso, a evolução das gerações culminou no aumento da transmissão de dados, conexão e velocidade de acesso à internet e aparelhos mais modernos (MERIJE, 2012). Safko e Brake destaca a evolução tecnológica dos celulares:

Os telefones celulares atuais possuem outras características além de fazer uma simples chamada telefônica. Os aparelhos celulares agora podem enviar mensagens de texto; realizar navegação na Internet; reproduzir música MP3; gravar memorandos; organizar informações pessoais, contatos e calendários; enviar e receber e-mails e mensagens instantâneas; gravar, enviar, receber e assistir a imagens e vídeos usando câmeras e filmadoras embutidas; executar diferentes toques, jogos e rádio; realizar push-to-talk (PTT); utilizar

\footnotetext{
${ }^{3}$ Dados retirados do site Teleco http://www.teleco.com.br/ncel.asp.
} 
infravermelho e conectividade Bluetooth; realizar vídeo-chamadas e servir como um modem sem fio para um PC (2010, p.266).

A evolução tecnológica do celular tem o seu auge com a chegada dos modelos smartphones "telefones inteligentes". Os smartphones apresentam-se como uma tecnologia que reúne várias mídias num só aparelho (telefone, internet, console de jogos, recursos dos computadores pessoais, entre outras) (MERIJE, 2012). Além disso, apresenta o que Straubhaar e LaRose (2004) denominaram de sistema multimídia texto, áudio e vídeo, recursos explorados em práticas de Mobile Learning.

Tendo em vista a variedade de recursos e a convergência, telefones celulares e smartphones oferecem um conjunto de possibilidades para a aprendizagem. Permite trocar informações, compartilhar idéias, experiências, resolver dúvidas, acessar uma vasta gama de recursos e materiais didáticos, incluindo texto, imagens, áudio, vídeo, notícias, conteúdos de blogs e jogos, tudo isso no exato momento em que faz necessário, devido à portabilidade (FERREIRA et al., 2012). A associação dos recursos dos aparelhos celulares e das redes de telefonia móvel com os da internet potencializou as possibilidades de acesso e compartilhamento de conteúdo (MERIJE, 2012), fator que confere uma nova dinâmica aos processos de comunicação como também de aprendizagem.

Não apenas telefones celulares e smartphones, mas as Tecnologias de Informação e Comunicação (TIC's) como um todo vem alterando a rotina e a dinâmica de diversos setores e o cotidiano da sociedade contemporânea. Assistimos a expansão vertiginosa desses aparatos e sua apropriação também pela Educação. São atribuídas as tecnologias digitais a ampliação da interação e acesso à informação.

Nesse sentido, Fedoce e Squirra (2011) apontam que o processo de ensinoaprendizagem passa por grandes transformações e todas as formas de escola devem estar atentas à inovação, uma vez que novos paradigmas estão definindo e delineando os modelos pedagógico-estruturais, transformações estas atribuídas em grande parte pela 


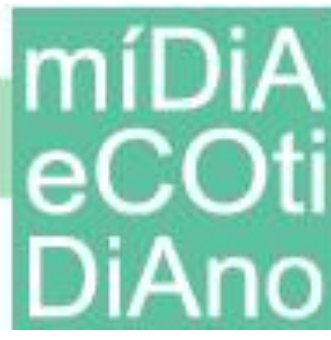

disseminação das TIC`s. Entretanto, pesquisas apontam ${ }^{4}$ que o uso e a resistência de TIC`s (como o celular) para o ensino dividem o mesmo espaço. Segundo Tapscott (1999) o uso da tecnologia de uma forma geral está entre a apreensão e o entusiasmo.

De acordo com Mülbert e Pereira (2011) as inovações tecnológicas oriundas do desenvolvimento das telecomunicações têm oportunizado acesso a diferentes ambientes e formas de aprendizagem. O que antes dependia de um aparelho ligado a uma estrutura fixa de rede, hoje conta com dispositivos móveis que também permitem o acesso a ambientes e recursos educacionais similares. Este cenário cria condições para o desenvolvimento de atividades de ensino-aprendizagem com dispositivos móveis e portáteis. Com isso, instituições e educadores se apropriam de celulares e smartphones para práticas de aprendizagem móvel, utilizados com objetivos pedagógicos para apoiar o processo de ensino-aprendizagem (TAROUCO et al.,2004).

\section{Mobile Learning: Apropriação de telefones celulares e smartphones para o ensino- aprendizagem}

De acordo com a definição de Mülbert e Pereira (2011), mobile learning ou mlearning "é o conceito que representa a aprendizagem entregue ou suportada por meio de dispositivos de mão tais como PDAs (Personal Digital Assistant), smartphones, iPods, tablets e outros pequenos dispositivos digitais que carregam ou manipulam informações". Os autores relatam que o termo mobile learning aparece pela primeira vez em uma publicação científica no ano de 2001 , onde se destaca a tendência e o potencial desta metodologia como futuro da aprendizagem, pautada nas vantagens de estudar em qualquer lugar e tempo.

Dentre os dispositivos que podem suportar o Mobile Learning, o telefone celular é o mais popular e acessível. Não requer investimentos financeiros por parte das instituições ou esperar de instâncias superiores, já que se trata de um aparelho comum no cotidiano "Se o computador ainda é um objeto restrito, o celular está presente em boa parte das escolas, nas mochilas dos alunos de diferentes classes sociais" (MERIJE,

\footnotetext{
${ }^{4}$ http://porvir.org/porfazer/10-dicas-13-motivos-para-usar-celular-na-aula/20130225.
} 


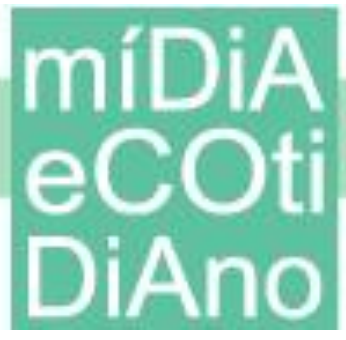

PPGMC

2012, p.81). O aparelho se apresenta como uma ferramenta disponível e que pode prontamente ser incorporada como objeto de aprendizagem.

O projeto Minha Vida Mobile - MVMob vem sendo desenvolvido desde 2005 e capacita estudantes e educadores para a produção de conteúdos audiovisuais com celulares - áudio, foto e vídeo. De acordo com o seu idealizador, Wagner Merije, as atividades do projeto geram exercícios de interpretação, síntese, categorização, criticidade, organização, relação grupal, autonomia, criatividade, num processo de articulação visual com os saberes da prática social dos educandos. Para isso, o MVMob realiza oficinas de produção de vídeos, fotos, áudios e notícias com o celular, premia e organiza mostras dos trabalhos, como também produz tutoriais e materiais de subsídio pedagógico. Segundo Merije (2012), essa metodologia de aprendizagem se mostra mais prazerosa e envolvente para os estudantes, pois inclui um objeto que faz parte do seu cotidiano, o telefone celular.

Em uma experiência no uso de celulares na disciplina de educação física para o registro de partidas esportivas e posterior análise de lances, movimentos e passes, Sena e Burgos (2010) destacam além da disseminação, o fato do celular ser um aparelho multimídia, que reúne texto, áudio, imagem e vídeo. Ainda, ressaltam a atratividade e a contextualização do processo de ensino-aprendizado a partir da apropriação desta tecnologia.

De acordo com a Filosofia da Tecnologia, a tecnologia é vista como sinônimo de progresso em relação a períodos anteriores. É comum também que a inserção de uma tecnologia a um processo ou atividade confira inovação.

Nesse aspecto, não só o Mobile Learning, mas o uso de TIC`s de uma forma geral deve ser visto com cautela. Na medida em que a tecnologia tem a capacidade de conferir inovação, atratividade, "modernizar" um processo, a apropriação dessas ferramentas pode se transformar mais em uma estratégia de marketing do que de aprendizagem. Dotar escolas e universidades de tecnologias pode ser um recurso para as instituições e governos. A tecnologia é inserida com o intuito de suprir e/ou mascarar problemas de aprendizado. Assim como qualquer bem material, a presença da 


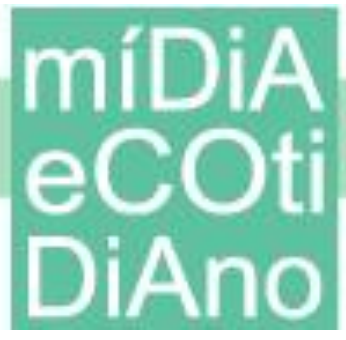

tecnologia permite inferir que tudo "está bem", o que ressalta a necessidade de um posicionamento crítico que esteja acima desses objetivos.

Principalmente, se levarmos em conta rankings de educação nos quais o Brasil não tem conseguido boas colocações. Mesmo tendo investido mais dinheiro na educação, a qualidade do serviço no país ainda deixa a desejar, de acordo com os dados apresentados nas pesquisas. Em pesquisa realizada pela empresa Pearson, que avaliou o ensino fundamental, que corresponde do $1^{\circ}$ ao $9^{\circ}$, dos 40 países avaliados, o Brasil ficou em $39^{\circ}$. Segundo um estudo feito pela OCDE - Organização para a Cooperação e Desenvolvimento Econômico, o país ficou com a $53^{\mathrm{a}}$ posição, entre 65 países que participaram do estudo sobre a qualidade do ensino ${ }^{6}$.

Ao trazermos a Filosofia da Tecnologia para esta discussão, a noção do conceito tecnologia se abre e permite uma análise mais estruturada de fenômenos como o $M$ Learning. É comum um reducionismo no uso e entendimento de tecnologia. Tecnologia não se refere apenas ao que é novo, moderno, a exemplo do celular. De acordo com Dusek (2006) a noção de tecnologia remonta as ferramentas dos primeiros humanos, portanto usar o termo apenas para definir computadores, tablets e celulares é, de acordo com a Filosofia da Tecnologia, uma definição restritiva do termo.

Nesse sentido, podemos afirmar que os processos de ensino-aprendizagem sempre foram permeados por algum tipo de tecnologia. A partir dos conceitos dessa corrente teórica é possível colocar que nunca houve uma existência que não seja atravessada pela tecnologia. Para Milton Vargas (1994) não há homens sem instrumentos, por mais rudimentares que sejam eles sempre estão lá.

\section{Projeto PALMA}

O projeto PALMA - Programa de Alfabetização na Língua Materna tem como objetivo desenvolver competências básicas de leitura e escrita por meio digital em jovens e adultos. A iniciativa vem sendo realizada em oito municípios do estado de São

\footnotetext{
${ }^{5} \mathrm{http}: / /$ veja.abril.com.br/noticia/educacao/brasil-aparece-em-penultimo-em-ranking-de-educacao

${ }^{6}$ http://veja.abril.com.br/noticia/educacao/com-mais-dinheiro-educacao-brasileira-decepciona
} 


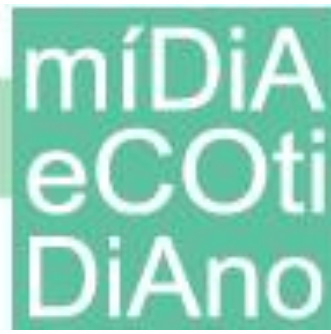

Paulo. Trata-se de um aplicativo para telefones inteligentes que consiste na combinação de sons, letras e imagens, propondo um aprendizado por associação de idéias. O aplicativo foi desenvolvido para complementar a educação formal de jovens e adultos que não sabem ler e escrever. Segundo uma professora que integra o projeto:

O uso dos smartphones diminuiu os índices de evasão e o aumento da frequência em sala de aula. "Eles tentam faltar menos, se preocupam em não deixar de fazer a atividade. Tornaram-se mais responsáveis", avalia a professora. Mas o principal diferencial em relação às aulas tradicionais, segundo ela, é que os alunos estudam por mais tempo (OJEDA, 2012).

A fala da professora reflete a visão de que a inserção de dispositivos tecnológicos confere "modernidade" a atividade, sendo o método "tradicional" aquele que não faz uso de dispositivos tecnológicos. A tecnologia aparece também como solução. Não podemos desconsiderar o potencial de uma tecnologia multifuncional como o celular é na atualidade, no entanto Dagnino (2008) alerta que a tecnologia não deve ser vista nem como salvação, nem como caixa de ferro.

No projeto PALMA, outro ponto que podemos destacar é o rompimento do tempo e espaço, que vêm sendo reconfigurados pelas TIC`s. O projeto aproveita a portabilidade do celular para proporcionar um aprendizado a qualquer hora, em qualquer lugar. De acordo com Lemos “A questão do tempo também é crucial nesta comunicação móvel já que cria temporalidades diferenciadas em relação a espaços diferenciados" (2009, p.28). A respeito da discussão sobre tempo e espaço:

Antônio Sabino de Sousa, colega de Nilma, quase chegou lá. Aos 62 anos, trabalha no departamento de reposição de uma loja de material de construção. Sai de casa às cinco da manhã. No ônibus que o leva para o serviço, liga seu smartphone, põe um fone de ouvido e faz os exercícios. As quatro da tarde, quando volta para casa, repete o ritual (OJEDA, 2012).

Aprendi a ler muito mais com o celular do que com a lousa. Antes não conseguia reter o que era passado nas aulas. O telefone ajuda a memorizar, pois eu levo para casa. É como se um professor estivesse do nosso lado, falando que tem que fazer de novo (OJEDA, 2012) 


\section{míDiA

O que diferencia o Mobile Learning realizado a partir de telefones celulares e smartphones dos demais modelos de ensino-aprendizagem mediados por tecnologias digitais é o dispositivo. Além de móvel este aparelho é portátil. “As tecnologias móveis ampliam o tempo e o espaço de estudo ao quebrar as barreiras temporais e espaciais, visto que o aluno pode aceder ao material de estudo em diversos momentos e contextos" (MOURA; CARVALHO, 2009, p.36). O Mobile Learning se mostra interessante também ao proporcionar uma educação continuada e para a execução de conteúdos sob demanda (TAROUCO et al., 2004).

\section{Escola com Celular}

Escola com Celular é um projeto realizado na cidade de São Vicente/SP que parte da constatação de que o telefone celular é muito mais do que um aparelho de comunicação. O celular é um recurso para trabalhar conteúdos curriculares, efetivar novas conexões e difundir a educação ambiental. A iniciativa trabalha pelo viés da sustentabilidade, com foco no descarte de resíduos e consumo.

A proposta consiste em, por meio de uma imersão em suas comunidades, os alunos estudam o tema "resíduos e consumo" e o princípio dos 3Rs (reduzir, reutilizar e reciclar). O resultado das observações é transformado em conteúdos públicos disponibilizados em uma rede social desenvolvida exclusivamente para o projeto. $\mathrm{O}$ celular é usado como instrumento de apoio para as atividades e serve como suporte para o acesso a informação, o registro, a comunicação e a discussão das descobertas e dos aprendizados dos alunos. O objetivo é ultrapassar os muros da escola: utilizar os dados da realidade para estimular a aprendizagem de conteúdos e desenvolver habilidades e competências. "Com as novas mídias móveis digitais, ampliam-se as possibilidades de consumir, produzir e distribuir informação, fazendo com que esta se exerça e ganhe força a partir da mobilidade física" (LEMOS 2009, p.28).

O projeto piloto foi executado em 2011, envolvendo alunos do ensino fundamental de escolas municipais e parte do currículo escolar organizado em projetos interdisciplinares que têm não só o ambiente escolar como contexto, mas também o 


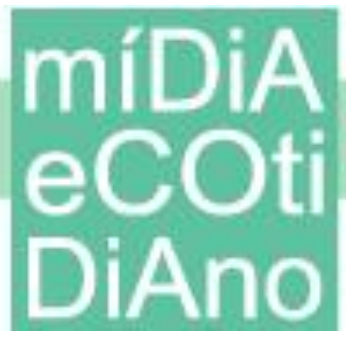

ambiente doméstico e a cidade, visando à integração dos espaços. O telefone celular é usado para a comunicação, através de mensagens de texto - SMS com tarefas, "pílulas de informação" e feedbacks das atividades e registro das observações por meio de vídeos, fotos e texto.

Para Lemos (2007b), a atual configuração comunicacional permite emitir, circular e se mover ao mesmo tempo. Essa configuração, decorrência da convergência, permite a criação de um novo ecossistema de informação e comunicação (STRAUBHAAR; LAROSE, 2004) onde os usuários também são fontes, produtores de conteúdo, intensificada com a portabilidade dos dispositivos.

Projetos como o PALMA e Escola com Celular ressaltam aspectos que vem sendo elencados como motivos para a apropriação de dispositivos móveis para o ensinoaprendizagem: possibilidade de feedback imediato, aprendizagem anytime/anywhere (a qualquer hora, em qualquer lugar) e um instrumento de suporte para a aprendizagem in loco, entre outros. Instituições como a UNESCO têm incentivado o uso de dispositivos comunicacionais móveis pela Educação, com destaque para o telefone celular. Recentemente, publicou um guia com recomendações para ajudar governos a implantarem tecnologias móveis nas salas de aula, além de elencar motivos para o seu uso. De acordo com o guia, entre os motivos para o uso de tecnologias móveis: permitir que se aprenda em qualquer hora e lugar; dar suporte a aprendizagem in loco; prover avaliação e feedback imediatos; melhorar a aprendizagem contínua e ampliar o alcance e a equidade em educação.

\section{Física e Química pelo celular}

Um projeto interessante é uma iniciativa independente realizada em uma escola pública com alunos da Educação de Jovens e Adultos - EJA em Campo Grande/MS. Percebendo a dificuldade em compreender o conteúdo da disciplina de física, o professor adotou o celular como ferramenta de apoio as aulas. A metodologia consiste em um jogo de perguntas no formato Quiz realizado a partir do Mobile Study (estudo móvel), uma ferramenta gratuita, disponível na Internet, que permite a criação de testes 


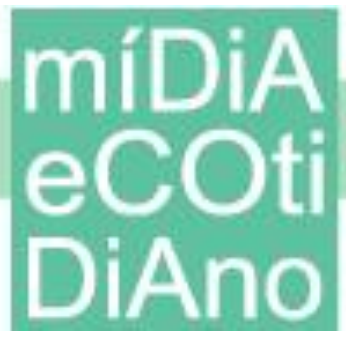

PPGMC

rápidos em várias áreas do conhecimento, acessado por computador ou celular, via SMS ou Bluetooth.

Com o acesso frequente ao conteúdo, possibilitado pela portabilidade do celular, os alunos podem acessar e estudar em qualquer momento, em qualquer lugar. Dessa forma, o professor conseguiu um mecanismo que ampliou o tempo e espaço de estudo, para além dos limites físicos da escola. Para Mülbert e Pereira (2011), o Mobile Learning tem como meta permitir um modo de educação mais flexível, capaz de criar novos contextos de aprendizagem através da interação entre pessoas, tecnologias e ambientes.

$\mathrm{O}$ uso do celular e smartphone para fins de ensino-aprendizagem também se estende a criação de aplicativos. De acordo com a pesquisa Perspectivas Tecnológicas para o Ensino Fundamental e Médio Brasileiro de 2012 a 2017, produzida pelo Horizon Project, a capacidade de executar aplicativos representa uma mudança fundamental no mercado de celulares e abre perspectivas para inúmeras utilizações no aprendizado.

Alunos da Universidade Federal do $\mathrm{ABC}$ desenvolveram um aplicativo que simula situações de laboratórios de química. O mLab é um laboratório virtual para smartphones e tablets e usa de recursos interativos, como chacoalhar o aparelho, para reproduzir experimentos. Por enquanto, o aplicativo conta com dois diferentes experimentos. No 'teste de chama', um elemento químico selecionado em uma lista é colocado sobre o fogo, alterando sua cor de acordo com a mistura. O 'ensaio de via úmida' mistura reagentes em um recipiente e apresenta o resultado após o celular ser chacoalhado.

Para os desenvolvedores, o aplicativo irá contribuir no aprendizado dentro e fora da sala de aula, ajudando os alunos a estudar química. O diferencial desta iniciativa está no fato dos alunos poderem replicar os experimentos de forma virtual, sem depender da infraestrutura exigida por um laboratório. Para Mülbert e Pereira (2011) exemplos como o mLab proporcionam um modo de educação mais flexível, ao libertar os estudantes da necessidade de estar em um laboratório físico, por exemplo, para estudar e realizar experimentos. Ainda, segundo a pesquisa do Horizon Project, umas das expectativas 


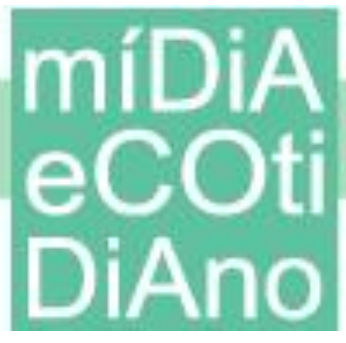

das pessoas com a expansão de dispositivos móveis é poder trabalhar, aprender e estudar sempre que quiserem e onde estiverem.

\section{Considerações Finais}

Diante dos exemplos é comum se impressionar com o Mobile Learning e gerar expectativas, atribuindo as TIC`s a capacidade de melhorar e solucionar problemas no aprendizado. Para o filósofo francês Lucien Sfez, nunca antes na história tivemos tantos meios de comunicação, porém, nos entendemos cada vez menos. O cenário atual, marcado pela disseminação das TIC`s, por exemplo, de acordo com Sfez, não assegura uma comunicação eficiente. Num mundo cada vez mais comunicante, compartilhado, informacional, se perder na confusão de enunciados pode se tornar fato (MEDEIROS, 2009).

Partindo da perspectiva de Sfez, são atribuídos aos dispositivos comunicacionais móveis à capacidade de proporcionar autonomia no processo de ensino-aprendizagem, pois na maioria dos casos, trata-se de aparelho pessoal e de uso individual. Questiona-se nesse aspecto a figura do professor, o que justificaria em partes o receio dessa apropriação. Nessa conjuntura, cabe ao professor o papel de direcionar e agregar valor as informações.

As tecnologias por si só não resolvem. Mülbert e Pereira (2011) alertam sobre a necessidade de olhar esses dispositivos para além de uma visão tecnocêntrica, buscar um conceito, um uso que vai além dos dispositivos, do foco tecnológico, que privilegie a união entre tecnologias e pessoas. Nesses casos, o foco não deve estar apenas no aprendiz ou na tecnologia e sim no encontro entre esses dois elementos.

Nesse sentido, buscando a Filosofia da Tecnologia, uma análise que se mostra dentro dessa perspectiva é a de sistemas tecnológicos ou categoria sistêmica (DUSEK, 2006), (DAGNINO, 2008). Dusek (2006) propõe uma abordagem da tecnologia a partir da proposição de Sistemas Tecnológicos. Como sistema, implica no envolvimento do homem com a tecnologia para ela funcionar. A categoria sistêmica trabalha a análise da tecnologia a partir de um conjunto composto pela própria tecnologia considerando a 


\section{míDiA

possibilidade de outros atores e agentes no processo (DAGNINO, 2008). Nas iniciativas apresentadas fica clara a necessidade do envolvimento e participação dos estudantes e professores, pois são eles que alimentam as atividades. Esses projetos só ganham sentido dentro do que esses autores propõem, da tecnologia como um sistema.

A pesquisa Perspectivas Tecnológicas para o Ensino Fundamental e Médio Brasileiro de 2012 a 2017 coloca o telefone celular num horizonte de um ano para que seja adotado massificamente pelas escolas. No entanto, os dados levantados por este artigo encontraram iniciativas diversificadas, porém pontuais. O estudo da tecnologia alerta que as previsões devem e requerem cautela.

A pesquisa aponta para dois fatores cruciais relacionados ao Mobile Learning. A falta de banda larga suficiente no Brasil e o despreparo dos professores. Ainda existe uma disparidade em relação ao acesso à internet de banda larga, especialmente fora dos centros urbanos. Enquanto grande parte da população do Brasil possui um smartphone, a infraestrutura para suportar a navegação é insuficiente. Apesar de existir muita inovação ocorrendo dentro da indústria de tecnologia, as ferramentas ainda não estão completamente integradas às escolas porque os professores não estão preparados para implementá-las.

Outra questão é que em se tratando de tecnologia, enquadra-lá sob o status de inovação e revolução faz parte de uma estratégia de marketing, o que a torna mais atrativa e consequentemente mais vendável, como também pode mascarar problemas.

De acordo com a pesquisa Perspectivas Tecnológicas, devido à popularização o celular vem se tornando uma escolha natural para a educação. Sua relevância se deve ao fato deste aparato agregar várias mídias, portabilidade e internet para trabalhos de campo. Em projetos como o PALMA, por exemplo, também podemos destacar o que Dagnino (2008) aborda, no fato da tecnologia estar ligada a transformação socioeconômica, trazendo a tona uma questão politica da tecnologia, que seria o seu uso para fomentar e proporcionar a mudança social, que neste caso se dá ao utilizar a tecnologia na alfabetização de jovens e adultos.

A partir dos exemplos apresentados, mesmo diante das ressalvas, é possível apontar telefones celulares e smartphones como instrumentos de transformação e úteis 


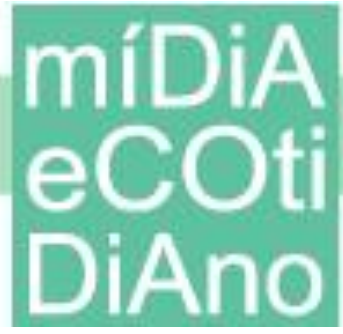

para fins de ensino-aprendizagem. Contudo, este artigo buscou destacar a necessidade de uma visão crítica nessa apropriação.

\section{Referências}

ANTONIO, José. C. Uso pedagógico do telefone móvel (Celular). Professor Digital, SBO, jan. 2010. Disponível em: <http://professordigital.wordpress.com/2010/01/13/uso-pedagogico-do-telefone-movelcelular/>. Acesso em: 10 mai.2012.

CASTELLS, Manuel. Afterword. In: Handbook of Mobile Communication Studies, Cambridge: MIT Press, 2008.

COSTELA, Antonio. F. Comunicação - Do Grito ao Satélite. Campos do Jordão: Editora Mantiqueira, 2002.

\section{CRIANÇAS BRASILEIRAS ESTÃO ENTRE AS QUE MAIS UTILIZAM DISPOSITIVOS MÓVEIS. Disponível}

<http://www.metodista.br/rronline/noticias/educacao/2012/10/criancas-brasileiras-

em: estao-entre-as-que-mais-utilizam-dispositivos-moveis>. Acesso em: 26 nov.2012.

DAGNINO, Renato. Neutralidade da ciência e determinismo tecnológico. Campinas, SP: Editora Unicamp, 2008.

DUSEK, Val. O que é tecnologia? Definindo ou caracterizando tecnologia. In: Filosofia da Tecnologia. São Paulo: Edições Loyola, 2006.

ESCOLA COM CELULAR. Disponível em: <http://www.escolacomcelular.org.br/>. Acesso em: 31 mai.2012.

EXPERIÊNCIA EM CAMPO GRANDE - MS. Disponível em: <http://www.seraoextra.blogspot.com.br/>. Acesso em: 31 mai.2012.

FEDOCE, Rosângela. S; SQUIRRA, Sebastião. C. A tecnologia móvel e os potenciais da comunicação na educação. LOGOS 35 Mediações sonoras: v.18, n. 2, 2011. Disponível em: < www.logos.uerj.br/PDFS/35/20_logos35_tema_livre_squirra.pdf >. Acesso em: 17 mai.2012.

FEENBERG, Andrew. O que é a Filosofia da Tecnologia? Conferência pronunciada para os estudantes universitários de Komaba, jun, 2003. 
FERREIRA, Jorge Brantes; SILVA, Jorge Ferreira da; CAMPOS, Helga; CARVALHO, Maria Luíza A. de; SABINO, Angilberto; SACCOL, Amarolinda; SCHLEMMER, Eliane. A disseminação $d a$ aprendizagem com mobilidade (M-learning). DataGramaZero: Rio de Janeiro, v. 13, n. 4, ago. 2012. Disponível em: <http://www.dgz.org.br/ago12/Art_02.htm>. Acesso em: 9 set. 2012.

FREIRE, Paulo; GUIMARÃES, Sérgio. Sobre educação: diálogos. v. II. Rio de Janeiro: Editora Paz e Terra, 2011.

JUNIOR, Walter. T. L. Big Data, Jornalismo Computacional e Data Journalism: estrutura, pensamento e prática profissional na Web de dados. Estudos em Comunicação: n. 12, 2012. Disponível em: < http://www.ec.ubi.pt/ec/12/pdf/EC122012Dez-11.pdf>. Acesso em: 18 fev.2013.

LEMOS, André. Comunicação e práticas sociais no espaço urbano: as características dos Dispositivos Híbridos Móveis de Conexão Multirredes (DHMCM). Comunicação, mídia e consumo, São Paulo, v.4, n. 10, p. 23-40, jul. 2007a. Disponível em: $<$ http://www.revistas.univerciencia.org/index.php/comunicacaomidiaeconsumo/article/v iewArticle/5016>. Acesso em: 21 abr.2009.

Cidade e mobilidade. Telefones celulares, funções pós-massivas e territórios informacionais. MATRIZes, São Paulo, n.1, p. 121-137, out. 2007b. Disponível em:<http://www.facom.ufba.br/ciberpesquisa/andrelemos/Media1AndreLemos.pdf> . Acesso em: 16 jun.2009.

. Cultura da Mobilidade. Famecos, vol.1, n. 40, 2009.

LIMA, João. E. R. Considerações sobre filosofia da tecnologia. Palestra proferida por ocasião da I Conferência Brasileira de Comunicação e Tecnologias Digitais da UMESP, 2007.

MEDEIROS. Eliane Cristina Gomes de. A comunicação de Lucien Sfez. Temática, Paraíba, n. 7 - julho. 2009. Disponível em: < http://www.insite.pro.br/2009/Julho/resenha_lucien_sfez_eliane.pdf $>$. Acesso em: 06 mai.2013.

MERIJE, Wagner. Mobimento: educação e comunicação mobile. São Paulo: Peirópolis, 2012.

MOURA, Adelina; CARVALHO, Ana Amélia. Peddy-paper literário mediado por telemóvel. Educação, Formação \& Tecnologias, vol.2, pp. 22-40, nov. 2009. Disponível em: <http://eft.educom.pt.>. Acesso em: 31 mai.2012. 
MÜLBERT, Ana Luisa; PEREIRA, Alice T. C. Um panorama da pesquisa sobre aprendizagem móvel (m-learning). In: Associação Brasileira de Pesquisadores em Cibercultura, 2011, Florianópolis. Anais do V Simpósio Nacional da ABCiber. Disponível em: http://simposio2011.abciber.org/anais/Trabalhos/artigos/Eixo\%201/7.E1/80.pdf>. Acesso em: 15 out.2012.

OJEDA, Igor. Uma vida nova na palma da mão. ARede $\mathrm{n}^{\circ}$ 80, mai. 2012. Disponível em: $\quad$ http://www.arede.inf.br/inclusao/edicoes-anteriores/190-edicao-no-80maio2012/5479-na-escola-uma-vida-nova-na-palma-da-mao>. Acesso em: 31 mai.2012.

PERSPECTIVAS TECNOLÓGICAS PARA O ENSINO FUNDAMENTAL E MÉDIO BRASILEIRO DE 2012 A 2017: Uma análise regional por NMC Horizon Project. Austin, Texas: The New Media Consortium Estados Unidos, 2012.

SAFKO, Lon; BRAKE, David. K. A Bíblia da mídia social: táticas, ferramentas e estratégias para construir e transformar negócios. São Paulo: Blucher, 2010.

SENA, Dianne; BURGOS, Taciana. O computador e o telefone celular no processo ensino-aprendizagem da educação física escolar. In: $3^{\circ}$ Simpósio Hipertexto e Tecnologias na Educação, 2010, Pernambuco. Anais Simpósio Hipertexto. Disponível em: <http://www.ufpe.br/nehte/simposio/anais/Anais-Hipertexto-2010/Dianne-SenaTaciana-Burgos.pdf $>$. Acesso em: 17 mai.2012.

STRAUBHAAR, Joseph; LaROSE, Robert. Comunicação, mídia e tecnologia. São Paulo: Pioneira Thomson Learning, 2004.

TAPSCOTT, Don. Geração digital: a crescente e irreversível ascensão da geração Net. São Paulo: Makron Books, 1999.

TAROUCO, Liane. M. R. et al. Objetos de Aprendizagem para M-Learning. Florianópolis: SUCESU - Congresso Nacional de Tecnologia da Informação e Comunicação, 2004. Disponível em <http://www.cinted.ufrgs.br/CESTA/objetosdeaprendizagem_sucesu.pdf>. Acesso em: 31 mai.2012.

UNESCO Policy Guidelines for Mobile Learning. Disponível em: < http://unesdoc.unesco.org/images/0021/002196/219641E.pdf $>$. Acesso em: 28 fev.2013.

UNIVERSITÁRIA DESENVOLVE LABORATÓRIO VIRTUAL PARA SMARTPHONES E TABLETS. Disponível: <http://www.metodista.br/rronline/noticias/tecnologia/2012/10/jornais-e-revistaspodem-ajudar-no-ensino-das-criancas> . Acesso em: 26 nov.2012. 


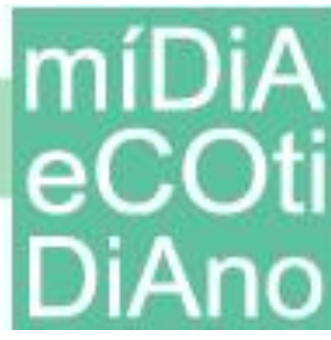

VARGAS, Milton. Ciência, Técnica e Realidade. In: Para uma filosofia da tecnologia. São Paulo: Alfa Omega, 1994. 